\title{
Depth of Cure and Microhardness of Nanofilled, Packable and Hybrid Dental Composite Resins
}

\author{
Mohamed El-Nawawy ${ }^{1}$, Lubna Koraitim ${ }^{1}$, Ossama Aboue latta ${ }^{2, *}$, Hanan Hegazi ${ }^{1}$ \\ ${ }^{1}$ Conservative Dentistry Dept., Faculty of Dentistry, Mansoura University, 35516, Mansoura, Egypt \\ ${ }^{2}$ Production Engin eering and Mechanical Design Dept., Faculty of Engineering, Mansoura University, 35516, Mansoura, Egypt
}

\begin{abstract}
Resin-based composites are used worldwide in dentistry as they are used in a huge variety of clinical applications, as an esthetic restorative material with excellent physical and mechanical properties when adequate polymerization is obtained. In this study, depth of cure and microhardness of three composites were measured and compared. A total of sixty human mandibular first molars were used. The teeth were divided into three main groups (20 teeth each) according to the composite resins that were used. In group I, Surefil (packable co mposite) was used as the restorative material. In group II, Esthet-X-improved (nanofilled composite) was used, while in group III Glacier (hybrid composite) was used. Each group was subdivided into four subgroups (five teeth each) according to the storage intervals (24 hours, one week, two weeks, and three weeks). In each group, occlusomesial cavities were prepared with diamond burs and restored with the composite, according to manufacturer's instructions. In all specimens, composite was applied to the cavity using incremental technique. All the restored teeth were subjected to in vitro thermal cycling and mechanical loading simulating a total of six months in vivo function. Depth of cure was evaluated using penetrometer and microhardness was measured using Vicker's microhardness tester. A significant difference in depth of cure and microhardness were found between the three composites used. Depth of cure and mic rohardness of the packable composite was better than the other two composites used. There was a fairly good correlation between the microhardness and the depth of cure for the three composite materials.
\end{abstract}

Keywords Depth of Cure, Microhardness, Nanofilled, Packable, Hybrid, Composite Resins

\section{Introduction}

The evolutionary development of filling materials leads to an increasing need for better tooth colored restorative materials to replace missing tooth structure and to modify tooth color and contour, thus enhance facial esthetics. Polymeric restoratives have continued to evolve into the direct restorative materials of choice mainly because of their superior aesthetic characteristics. Currently, composites are the most widely used materials in restorative dentistry[1].

Composites consist of a mixture of two or more materials. Each of these materials contributes to the overall properties of the composite. Resin based composites are possibly the most universal material available in dentistry as they are used in a huge variety of clinical applications, ranging from filling material, luting agent, indirect restorations and metal facing for endodontic posts and cores[2].There is no one ideal dental composite materials available to the clinician, but the commercial materials that comprise the current armamentarium are of high quality and when used

* Corresponding author:

abouelatta@mans.edu.eg (OssamaAbou elatta)

Published online at http://journal.sapub.org/ajbe

Copyright (C) 2012 Scientific \& Acad emic Publishing. All Rights Reserved appropriately, have proven to deliver excellent clinical outcomes of adequate longevity[3].The depth of polymerization is of vital importance not only in order to achieve optimum mechanical properties including hardness but also to ensure that the clinical problems do not arise due to partially polymerized material in the base of the cavity[4].Hybrid or blended composites contain a graded blend of small and colloidal silica filler particles to achieve an optimal balance among the properties of strength, polymerization shrinkage, wear resistance and polish ability[5].

Dental composite restorations have a major drawback: the degree to which they cure which is proportional to the amount of light to which they are exposed. So, they polymerize to a certain depth which varies with the penetration of a light beam in the bulk material. This extent of cure has been termed (depth of cure) and has significant influence on both physical and biological properties of restorations [6].The depth of cure is the depth to which the light is able to harden the material. This does not mean that the hardness in the lower areas is of the same magnitude at the top of the irradiated sample. A lthough there exists no general accepted definition on depth of cure and how to determine it quantitatively, there is a sort of agreement that depth of cure is limited to that distance from the top surface of a cylindrical sample where no more resinous material can 
be scratched off[7]. Because dental restorations need an optimal poly merization level, investigators have studied the effect of different parameters on the depth of cure. It was found that the depth of cure of light activated composite resins depends on the material filler composition, its shade, translucency, the intensity of light source and the distance fro $m$ the curing tip[8-12].

The depth of cure of visible light activated composites has been accomplished by many researchers[13-23]. Overall depth of cure of the 15 micron filler series was somewhat better than that for the 2 micron filler series[13].Large particle hybrids had the greatest depth of cure, followed by small particle hybrid then micro-filled composite[14]. The depth of cure was affected by composite composition rather than irradiance from light units [15]. The hardness of composites decreased with increasing the depth[16]. At the composite surface, filler type, exposure duration and resin shade predominated as the most influential factors, respectively[17]. The cure of top surfaces of light activated materials was not greatly affected by light intensities but curing of the inner aspects of the materials was affected by light intensities[18]. By comparing he physical properties of three packable hybrid resin-based composites with those of a conventional hybrid and a microfill composite material advocated for use as posterior restorative materials, packable composites had a significantly greater depth of cure than all other resin-based composites, followed in decreasing order by conventional hybrid composite and microfilled composite[19].

By studying depth of cure, polymerization shrinkage and microhardness of packable, ion-releasing and hybrid composites, the depth of cure showed no statistically significant differences among all materials tested[20]. The curing depth of polyacid-modified composite resins was independent of post-cure, but differed significantly among materials and shade and the curing depth greatly varied among the materials[21]. New-formulated resin-based composites showed better performance concerning depth of cure compared to conventional materials[22]. Properties currently used to evaluate depth of cure (microhardness, degree of conversion or scraping methods) fail to detect this transition, which results in overestimation of the depth of cure[23].

On the other hand, hardness is defined as the ability of the material to resist permanent surface indentation, penetration and abrasion.Hardness is indicative for the ease of finishing of a structure and its resistance to scratching[24 ]. Besides, the indentation produced on the surface of a material from an applied force of a sharp point or an abrasive particle results from the interaction of numerous properties. Among the properties that are related to the hardness of the material, there are strength, proportional limit and ductility. Hardness of a brittle material such as composite resin can be determined by Vickers and knooptests, which are classified as microhardness tests in comparison with Rockwell and Brinellmacrohardness tests[25].
When studying the effect of volume fraction and particle size on the microhardness of eight visible light cured composite resins with a wide range of particle size, a direct proportional relation existed, as the particle size increased the hardness increased[26]. A significant correlation between the volume fraction of filler and knoop hardness number and no correlation was observed between the degree of conversion and the surface hardness in any of the composite resins tested[27].

A progressive increase in microhardness for four weeks measurements in testing microhardness of eight visible light-cured and self-cured composite resin specimens (dry or wet), followed by stabilization until the end of the test[28]. Filler type was found to be the most important variable at the top surface[29], when studying the effect of the light intensity, filler type, the duration of exposure and the thickness on the microhardness of composite resins. Microhardness values have been improved due to higher initiator concentration and exposure times the microhardness values[30]. The microhardness values for the light cured glass ionomer were the lowest and composite resins and polyacid-modified composites had the highest values[31].

In some cases, packable composites were unlikely to offer improved clinical performance over well-placed non-packable composites[32]. Besides the filler content level and filler size, some factors like matrix-filler interactions highly influenced the microhardness and wear behavior of the materials[33]. The microhardness of the nanofilled composites was equivalent to or higher than those of the other hybrids, microhybrids and microfill composites[34]. The indirect laboratory processed composite exhibited higher mean values for hardness and degree of conversion but at $4 \mathrm{~mm}$ depth, the packable composites exhibited significantly greater hardness than other direct composites tested[35].

In general, indirect resin composite shows poorer mechanical properties than hybrid composites[36]. By studying the quality of polymerization of hybrid composite resins, it was found that each product had different microhardness values and the repeated thermal stimu lus had no specific effect on the change of mic rohardness [37]. The nanofilled resin composite displayed the higher microhardness values for curing regimes[38]. One-step polishing systems may be successfully used for polishing nanocomposites that contain nanoparticles and a micro-hybrid composite[39]. Clearfil Majesty ${ }^{\mathrm{TM}}$ Posterior demonstrated a higher microhardness, less surface roughness, and higher wear resistance when compared with the some tested materials for both poly merization types [40]. The mode of polymerization and the lightcuring time did not affect the hardness of the nanofilled composite resin, and increasing the lightcuring time did not improve the hardness of the bottom surface of the composite resin[41]. The effectiveness of cure at the top and bottom surface was not affected by soft-start polymerization mode[42]. For bulk fill materials, the ISO 4049 method overestimated depth of cure compared to depth of cure determined by Vickers 
hardness profiles[43].

This work aims to evaluate and to compare measurements of depth of cure and microhardness of three composites resinsat different storage time. The second research hypothesis was that the depth of cure determined by a penetrometer method would correlate with the measured microhardness.

\section{Materials and Methods [44]}

\subsection{Material}

Sixty sound human mandibular first mo lars were collected from a dental clinic from patients with ages ranged from 25-35 years. The collected teeth were cleaned from debris and blood by a tooth brush and soap under running water after storing them in $1 \% \mathrm{H}_{2} \mathrm{O}_{2}$ for 24 hours. The collected teeth were examined using light microscope (PHMG, Olympus Optical Co. Ltd., Tokyo, Japan) to select molars that were free from cracks[45].The extracted teeth were stored in $0.2 \%$ Sodium Azide (has antibacterial activity) at room temperature before preparation and restoration[46 ].The materials used in this study are listed in Table 1.

\subsection{Specimen Preparation}

Intact teeth were mounted in auto-polymerizing acrylic resin blocks (Pekatray, Bayer Dental Leverkusen, Germany) that were confined by stainless steel holders. Each holder held three teeth positioned with crowns in proximal contacts and long axis parallel to the sides[47]. The tooth in between the axial teeth was used only to obtain firm contact areas as shown in Figure 1(a). Class II (occlusomesial) cavities were prepared with an occlusal box of dimensions $2.5 \mathrm{~mm}$ depth and $2 \mathrm{~mm}$ width. A proximal bo x of $3.5 \mathrm{~mm}$ depth and $3 \mathrm{~mm}$ width was made as shown in Figure1(b), using high speed handpiece (NSK, Tokyo, Japan) with continuous air-water cooling system[45].

In order to create standardized occlusomesial cavities with a defin ite form and size, the preparation was made using a cylindrical diamond bur (Mani, Tokyo, Japan) with a rubber stop adjusted to the required depth[48-48], as shown in Figure 1(c). For adjusting the cavity width, a vernier caliper was used. A new point was used for every three preparations to standardize the sharpness and cutting efficiency of the diamond instruments for all the specimens.

\subsection{Specimens Grouping}

Sixty molars were divided into three main groups according to the type of composite resins that were used. Each group consisted of 20 teeth. In group I Surefil was used as the restorative material, in group II Esthet-X-Improved was used, while in group III Glacier was used. Each group was subdivided into four subgroups (five teeth each) according to the storage intervals (24 hours, one week, two weeks and three weeks)[50].

\subsection{Restorative Procedures}

After the preparation of each tooth, the cavity was dried using gentle air blast and a transparent matrix in a tofflemire matrix retainer (ProduitsDentaires SE, Switzerland) was used and held in place with light reflecting wedges (Dentalez Group, Malvern, USA) as shown in Figure 1(d). Phosphoric acid etchant gel $37 \%$ was applied to the enamel and dentin as shown in Figure 1(e), and left for 15 seconds. After that it washed with water spray for ten seconds and air dried by oil free compressed air. Excess water was removed without over drying the dentin[45]. The Prime \& Bond NT bonding agent was applied to the etched enamel and dentin using a disposable applicator tip as shown in Figure 1(f), for 20 seconds.

Table 1. Packable, Nanofllled and Hybrid Materials

\begin{tabular}{|c|c|c|}
\hline Materials & Composition & Manufacturer \\
\hline $\begin{array}{l}\text { Surefil } \\
\text { (Packable composite) } \\
\text { Midi/Minifilled }\end{array}$ & $\begin{array}{l}\text { Resin Matrix: urethane modified (Bis-GMA) dimethacrylate (10-15\%) wt } \\
\text { Polymerizabledimethacrylate resin (5-10\%) wt. } \\
\text { Amorphns fused silica } 1-2 \% \text {. } \\
\text { Inorganic Filler: Barium boranflouoruAluminosilicate glass } 60-70 \% \text {. }\end{array}$ & $\begin{array}{l}\text { Dentsply Caulk. } \\
\text { Milford, DE } 19963-0359 \\
\text { U.S.A. }\end{array}$ \\
\hline $\begin{array}{l}\text { Esthet-X-improved } \\
\text { (Micro matrix } \\
\text { nanofilled composite) }\end{array}$ & $\begin{array}{l}\text { Resin Matrix: Bis-GMA adduct Bis EMA adduct, triethylene glycol dimethacrylate, } \\
\text { camphorquinone (CQ) } 25 \% \text { wt. } \\
\text { Silica Amorphous } 4 \% \text { wt. } \\
\text { Titanium dioxide } 2 \% \text { wt. } \\
\text { Inorganic Filler: combination of Barium boron fluoroalumino silicate glass with mean } \\
\text { particle size below } 1 \mu \mathrm{m} \text { and nanofiller silica (Particle size } 0.04 \mathrm{Mm}) 70 \%\end{array}$ & $\begin{array}{l}\text { Dentsply Caulk. } \\
\text { Milford, DE } 19963-0359 \text { U.S.A. }\end{array}$ \\
\hline $\begin{array}{l}\text { Glacier } \\
\text { (Hybrid composite) }\end{array}$ & $\begin{array}{l}\text { Resin Matrix: Bisphenolglycidyl methacrylate (Bis-GMA). Urethane dimethacrylate (18- } \\
40 \% \text { ) wt. } \\
\text { Inorganic Filler: Barium silica glass }(60-80 \%) \text { wt }\end{array}$ & $\begin{array}{l}\text { Southern Dental Industries (SDI) } \\
\text { Bayswater } 3153 \text {. Australia. }\end{array}$ \\
\hline
\end{tabular}


The excess was gently air thinned for five seconds until a uniform glossy appearance was obtained, then bonding agent was light cured) (MEGA-PHYSIK Dental, D-76437- Rastatt, Germany) as shown in Figure $1(\mathrm{~g})$, for ten seconds with a light curing unit (Chromalux light cure unit). In all specimens composite was applied to the cavity using the incremental technique, Figure 1(h). The thickness of each increment was about $2 \mathrm{~mm}$ and each increment was cured for 20 seconds according to manufacturer instructions.

\subsection{Curing Procedures}

According to the manufacturer instructions, the first layer was applied with a suitable condenser (Co mpo-Sculp: DD 3, Sutr dental manufacturing, CHICO, CA). The composite resin was adapted to the cavity floor and walls, then light cured for 20 seconds. The second layer was applied similarly, then the anatomical occlusal surface was carved using shaping-sculpting instruments (Compo-Sculp: DD 1, 2, Sutr dental manufacturing, $\mathrm{CHICO}, \mathrm{CA}$ ) and light cured for 20 seconds as shown in Figure 1(i).

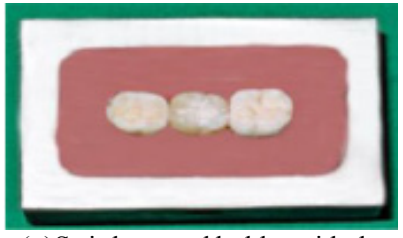

(a) Stainless steel holder with the teeth in proximal contact

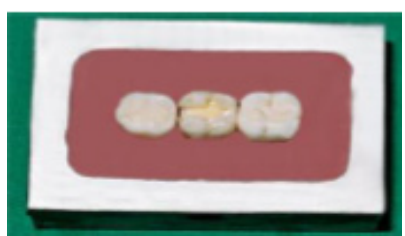

(c)Occlusomesial cavity prepared with cylindrical diamond bur

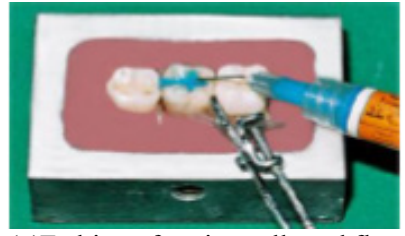

(e)Etching of cavity walls and floor

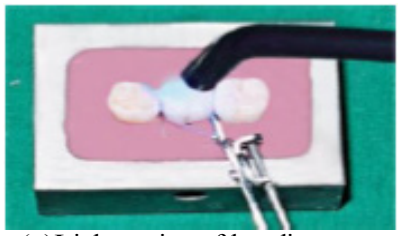

(g)Light curing of bonding agent

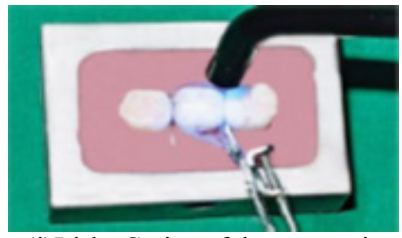

(i)Light Curing of the composite

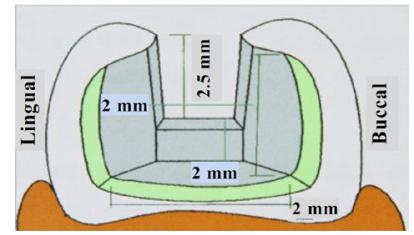

(b)Schematic drawing for occlusomesial cavity preparation

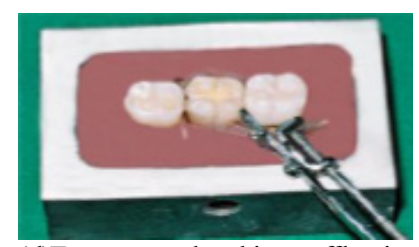

(d)T ransparent band in a tofflemire retainer placed against the tooth
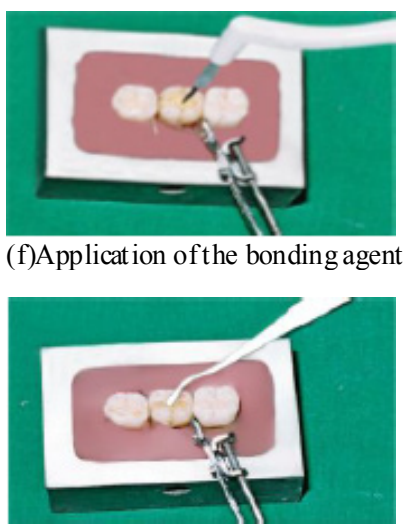

(h)Application of the composite

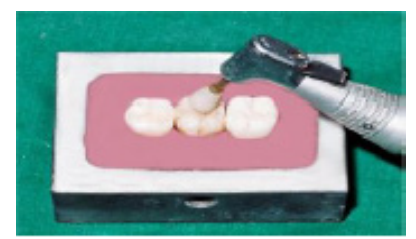

(j)Finishing of the composite
(f)Application of the bonding agent

Figure 1. Specimen preparation

\subsection{Finishing and Polishing}

The finishing was immediately done, gross excess was removed and a general outline form was established with diamond finishing instruments. Additional finishing was done by the use of "Enhance" finishing system (Dentsply Caulk, Mil ford, DE 19963-0359, USA) as shown in Figure 1(j). A high luster was established by using "Pogo" one step diamond micro-polisher system (Dentsply Caulk, Mil ford, DE 19963-0359, USA), according to the manufacturer's instructions. All the specimens were subjected to a total of six months in vitro simulated in vivo function[51], by exposing the restoration to thermal cycling and mechanical loading (Conservative Department Lab, faculty of Dentistry, Tanta University, Egypt).

\subsection{Ther mal Cycling}

For thermal cycling, all the specimens were thermocycled between $5 \pm 2^{\circ} \mathrm{C}$ and $55 \pm 2^{\circ} \mathrm{C}$ for 300 cycles, with a dwell time 2 minutes and 10 seconds trans fer time[51].

\subsection{Load Cycling}

All specimens were fixed in mounting rings. The mounting ring was attached to the lower member of a custom - made loading machine which acted as the mandibular element, while a uniaxial load of $49 \mathrm{~N}$ was applied using a rounded end metal rod which was fascinated to the upper member of the machine, Figure 2.

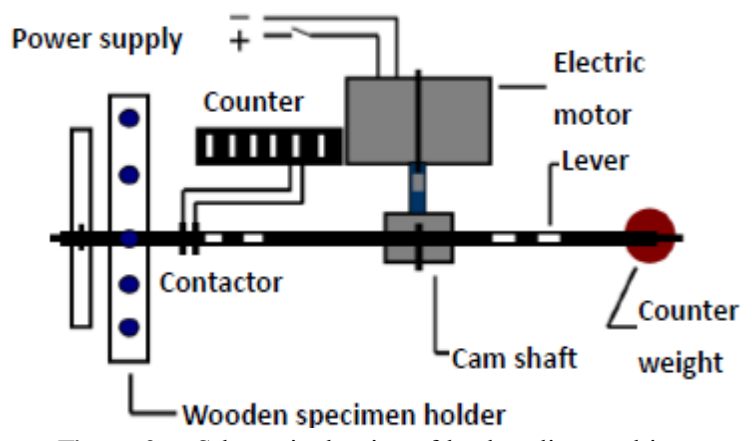

Figure 2. Schematic drawing of load cycling machine

A $3 \mathrm{~mm}$ diameter of the root was chosen to allow contacting restoration. A cam was attached between the two portions stabilizing the degree of opening $(10 \mathrm{~cm})$ of the mandibular portion according to measurements taken from the natural tempro-mandibular joint movement. All specimens were subjected to 120,000 loading cycles corresponding to six months of clinical service thus simulating the clinical conditions as much as possible[51]. Each group was subdivided into four subgroups according to the storage period intervals. Subgroup specimens were stored in artificial saliva for one day, one week, two weeks and three weeks.

\subsection{Depth of Cure Test}

The depth of cure of a visible-light activated resin has been the subject of considerable laboratory research. Even after more than 25 years of clinical use, there are still 
controversies about the depth of cure of a visible light activated resin. A number of different techniques have been emp loyed to measure the properties of the polymerized resin composite most distant from the light source[52].

Tefflon cylindrical moulds were prepared, as shown in Figure 3. Its outside dimensions were $24 \mathrm{~mm}$ in diameter and $6 \mathrm{~mm}$ height. Cylindrical cavities of $4 \mathrm{~mm}$ in diameter were prepared in the center line of the moulds [4]. The cylindrical mould was placed on a cellu lose acetate matrix strip resting on a flat black disk and the mould filled was with the composite. The composite was dispensed directly from its container into the cavity of the mould as shown in Figure 4.

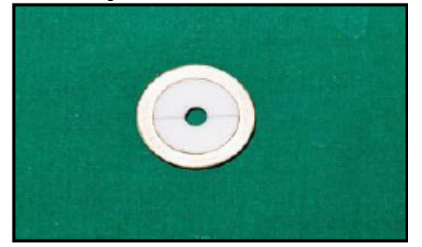

Figure 3. Tefflon cylindrical mould

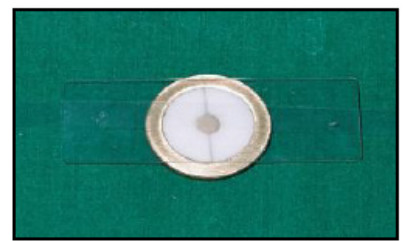

Figure 4. Applying a glass slab to remove the excess of material

A second stripe of a cellulose acetate was placed on top. A glass slab was pressed on the top of this to express the excess material. The glass slab was then removed and the material was cured from one end of the mould for 30 seconds using alignment ring as illustrated in Figure 5. The mould (a) was placed on the base (b) and aligned within the mould alignment ring (c). The light tip alignment ring (d) was placed above the mould. This allows light tip (e) to be positioned concentrically with the cavity in the mould, then the composite was cured for 30 second using light curing unit (Chromalux, MEGA-PHYSIK. Dental. D-76937. Rastatt, Germany). Ten specimens were made for each composite material of the same shade $\left(\mathrm{A}_{2}\right)[4]$.

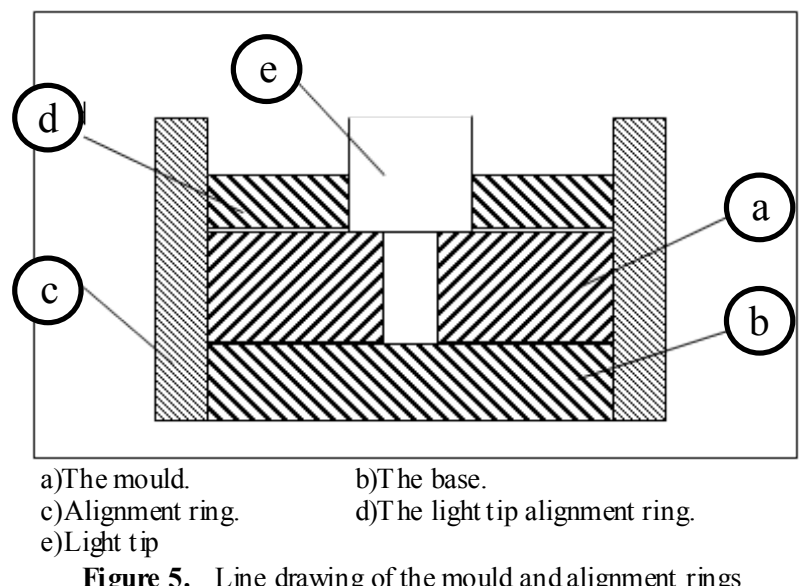

The mould was removed from the alignment ring and the cellulose acetate strips were discarded. The mould was inverted and was ready for testing by penetrometer (Fabricated and manufactured in metrology lab, department of production engineering and mechanical design, faculty of engineering, Mansoura University), as shown in Figure 6.

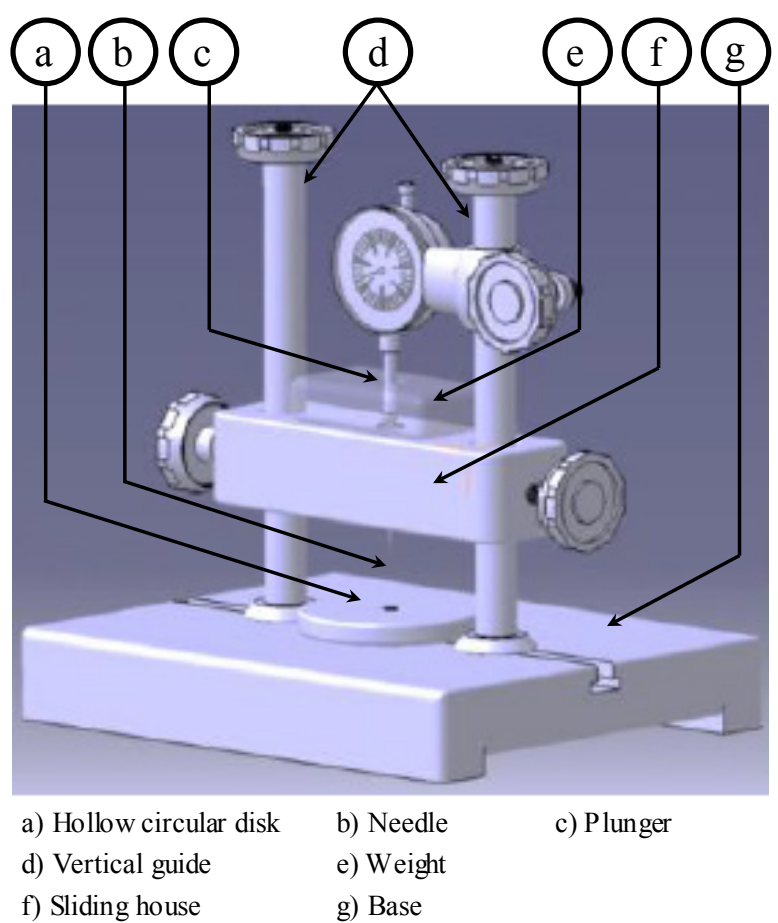

Figure 6. Penetrometer apparatus

It consists of a penetrometer needle, whose position can be established rapidly. The position of the needle was realized using a dial indicator gauge (Dial indicator testing machine, Maher, Germany) which can be zeroed at any position. The accuracy of the reading dial indicator gauge is $0.01 \mathrm{~mm}$. A freely sliding housing (f) is in contact with the removable part of the dial gauge plunger (c). A cylindrical penetrometer needle (b), $0.5 \mathrm{~mm}$ diameter, is mounted on the sliding house. Initially, the readout is zeroed when the needle contacts the base of the instrument. Therefore, when the test is being performed, the value indicated on the dial indicator gauge is the height of the hardened material[4]. This method has advantages over other methods used to test the depth of cure in that a single reading only is required to obtain depth of cure.

All the moulds used with the penetrometer apparatus had the same outer diameter of $24 \mathrm{~mm}$ in order to facilitate the alignment of the center line of the mould with that of the penetrometer needle when the mould was placed in the right-angled position using two vertical columns (d). A circular block (e) was attached to the top of the sliding housing representing a mass of $250 \mathrm{gm}$. The base of the apparatus is a hollow circular disk on which the moulds were placed (a).

After specimen preparation was fin ished, the mould was inverted and positioned so that its center was beneath by the penetrometer needle. A mass of $1000 \mathrm{gm}$ was placed on the freely sliding housing, so the applied force will be $12.5 \mathrm{~N}$. 
This force exerted through a $0.5 \mathrm{~mm}$ diameter needle resulted in a stress of $62 \mathrm{MPa}$ [4]. The needle was lowered, under the weight of both sliding house and the $1000 \mathrm{gm}$ block for 30 seconds after the end of curing time, penetrating the uncured material and the reading was recorded of the dial indicator gauge 15 seconds later. The later reading gives a direct measurement of depth of cure, or more precisely, depth of hardened material[4].

\subsection{Microhardness Test}

The mic rohardness test is a simple and reliable method to reflect the degree of conversion at different depths of resin composite. In this study mic rohardness measurements were used as an indicator of the degree of poly merization of light-curing resin composite materials which is a relative simple and accurate technique[53]. Microhardness measurements are in particular useful since a s mall change in degree of polymerization may yield a large change in hardness.

A total of 30 specimens, ten specimens of each composite type of the same shade $\left(\mathrm{A}_{2}\right)$ were prepared in a round stainless steel mould of $6 \mathrm{~mm}$ diameter and $3 \mathrm{~mm}$ thickness[36].The round mould was placed on a cellulose acetate strip resting on a flat surface, then the mould was filled with the composite restorative material which was dispensed directly from its container into the cavity of the mould, a second layer of a cellu lose strip was placed on the top, a glass slab was pressed on the top of this to express the excess material. The composite was cured from both sides for ten seconds each using a light curing unit. Cellulose acetate strips(Vicker's hardness tester, SM-7, future grope, Japan.) were used in this test to produce a very smooth surface of the composite specimens, Figure 7.

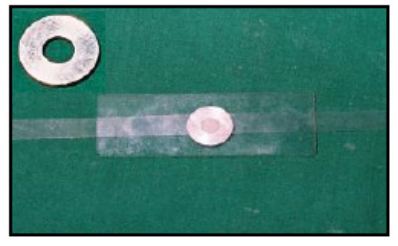

(a) Application of the composite.

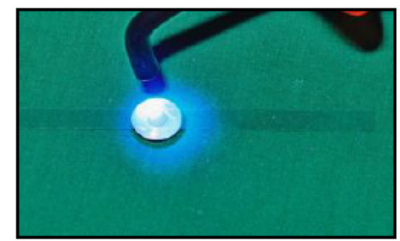

(b) Light curing of the composite.

Figure 7. Specimen preparation for microhardness test

The prepared specimens were taken out and stored in distilled water at room temperature for 24 hours. Microhardness of the composite specimens was measured on each side using a Vicker's microhardness tester as shown in Figure 8.

Six measurements for each specimen were taken. The specimenwas placed horizontally on a glass slide and mounted on a holder on the microscope stage. The specimen surface was examined microscopically and the indenter was then moved into position and the microscope stage raised steadily until the required load was appliedby the indenter upon the specimen. The applied load was $25 \mathrm{gm}$ and the dual time was 5 seconds. Under an optical microscope, each indentation was measured diagonally from one edge of the diamond shaped impression to the other edge. The average diagonal lengths of the indentations were then measured[36]. The Vicker's microhardness (Hv) was calculated using the following equation:

$$
H_{v}\left(\mathrm{~kg} / \mathrm{mm}^{2}\right)=1854.4\left(P / \mathrm{d}^{3}\right)
$$

where

$\mathrm{P}=$ applied indentation load.

$\mathrm{d}=$ diagonal length of the impression.

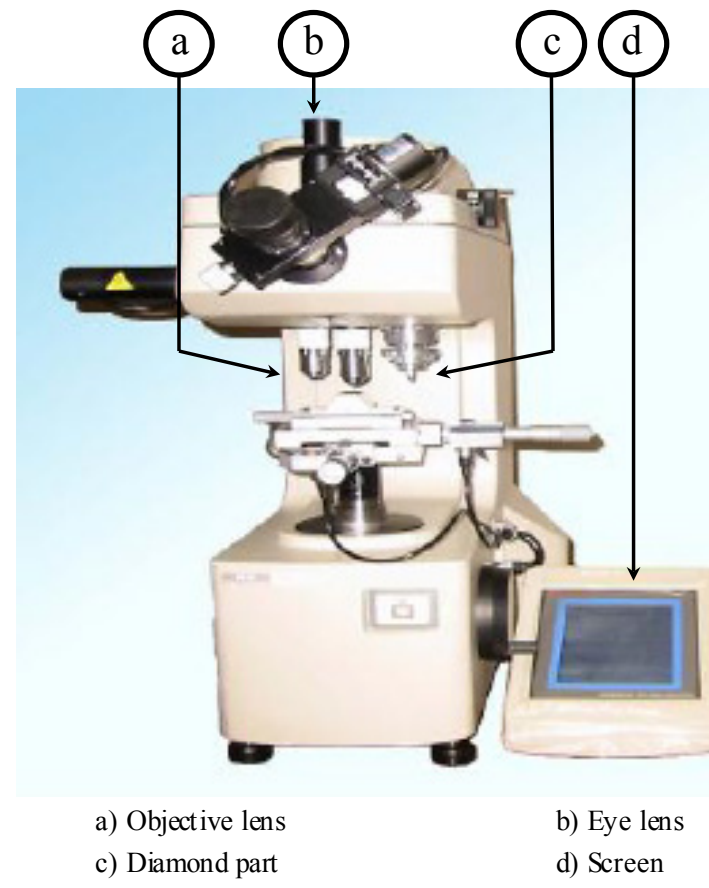

Figure 8. Vicker's microhardness tester

All the collected results were statistically analyzed using analysis of variance (ANOVA). A Duncan's multiple range test was used to interpret the data. The statistical analysis of data was conducted using Microsoft Excel and SPSS software 12.0 (SPSS Software, München, Germany).First part of the data is descriptive in form of mean $(\mathrm{X})$, standard deviation(+SD)and probability (P). Second part isanalytic to test statistical significant difference between groups.One way ANOVA test was used for determination of significant difference between groups, paired sample student's t-test was used to compare significance different for different storage interval periods in the same group and Post Hoc Test: LSD[least significant difference] to test significant difference intra - groups.

\section{Results}

\subsection{Depth of Cure}

The analysis of variance test ANOVA was used to compare the mean values of the depth of cure of the three restorative materials. The mean values, the standard deviation and results of the ANOVA test were represented in Figure 9. 


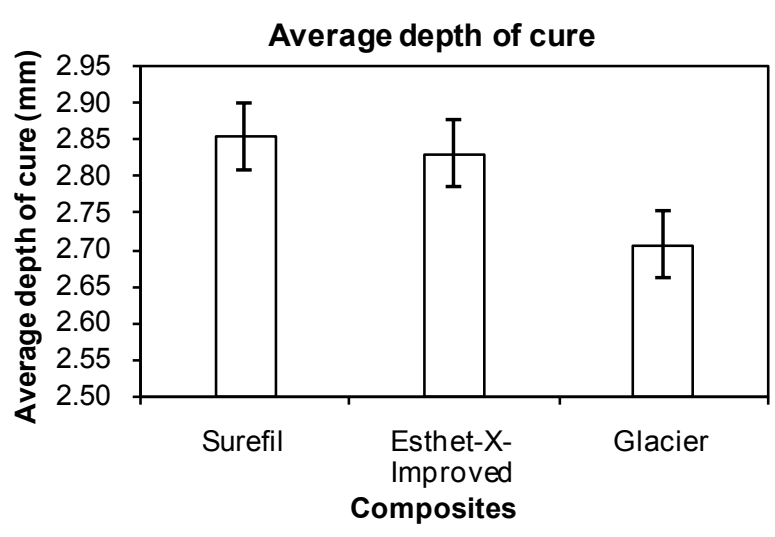

Figure 9. Comparison between mean values of the depth of cure of the three composite resins

There was a statistical significant difference between the mean values of depth of cure of Surefil, the mean values of the depth of cure of Esthet-X-Improved and the mean values of the depth of cure of Glacier, where $\mathrm{P}<0.05$. The Post hoc test (LSD) least significant test was used to compare between the mean differences of depth of cure of the three composite materials as listed in Table 2.

Table 2. Statistical comparison bet ween mean values of the depth of cure in $\mu \mathrm{m}$ of the three composites

\begin{tabular}{|c|c|c|c|}
\hline \multicolumn{2}{|c|}{ Composites } & $\begin{array}{c}\text { Mean } \\
\text { Difference }\end{array}$ & $\mathrm{P}$ \\
\hline \multirow{2}{*}{ Surefil } & Glacier & $0.153^{*}$ & 0.008 \\
& Esthet-X-improved & 0.016 & 0.768 \\
\hline \multirow{2}{*}{ Esthet-X-improved } & Glacier & $0.137^{*}$ & 0.017 \\
& Surefil & 0.016 & 0.768 \\
\hline \multirow{2}{*}{ Glacier } & Esthet-X-improved & $0.137^{*}$ & 0.017 \\
& Surefil & $0.153^{*}$ & 0.008 \\
\hline
\end{tabular}

* Significant differences at $5 \%$ level, $\mathrm{P}<0.05$

The Post Hoc (LSD) test showed statistically significant difference between the mean values of depth of cure of Surefil versus Glacier, $P=0.008$ and Glacier versus Esthet-X-Imp roved, $P=0.017$. The Post Hoc test (LSD) test showed no statistically significant difference between the mean values of depth of cure of Surfil versus Esthet-X-Imp roved, $\mathrm{P}>0.05$.

\subsection{Microhar dness}

The analysis of variance test ANOVA was used to compare between the mean values of the microhardness of the three restorative materials. The mean values, the standard deviation and results of the ANOVA test were represented in Figure 10.

There was a high significant diffe rence between the mean values of microhardness of Surefil, the mean values of microhardness of Esthet-X-Improved and the mean values of microhardness of Glacier, where $\mathrm{P}<0.05$.The Post-hoc test (LSD) least significant test was used to compare between the mean difference values of mic rohardness of the three composite materials.

A high significant difference was found between the mean values of microhardness of Surefil versus Glacier, $\mathrm{P}=$
0.000, Glacier versus Esthet-X-Improved, $\mathrm{P}=0.000$ and Surfil versus Esthet-X-Imp roved, where $\mathrm{P}<0.05$.

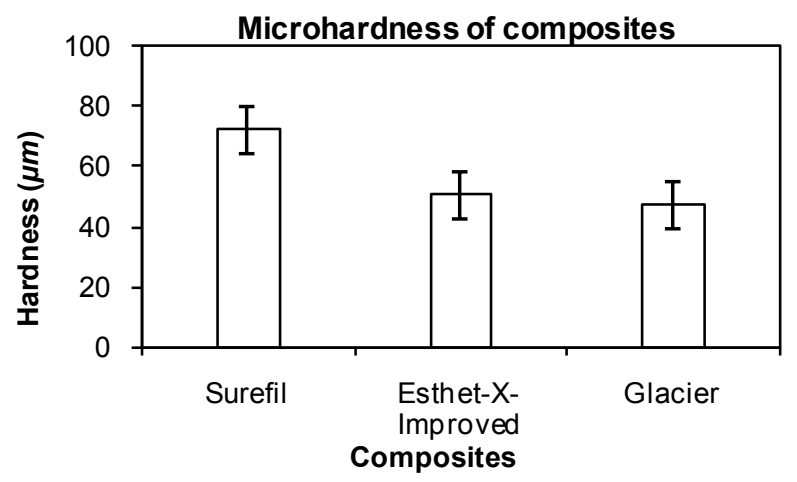

Figure 10. Comparison between the mean values of the microhardness of the three composite resins

\subsection{Correlation between depth of cure and microhar dness tests}

In the standard tests for correlation, a correlation coefficient is tested against the hypothesis of no correlation, i.e., $\mathrm{R}=0$. It is possible to test whether the correlation coefficient is equal to or different from another fixed value. Correlation coefficient test for depth of cure and microhardness of the three composites showed a good correlation as $(\mathrm{R}=0.709)$ and $(\mathrm{P}<0.05)$ as shown in Table 3.

Table 3. Correlation coefficient test for depth of cure and microhardness of the three composites

\begin{tabular}{|l|c|c|}
\hline & Depth of cure & \\
\hline \multirow{3}{*}{ Microhardness } & $0.709^{* *}$ & Correlation coefficient (r) \\
\cline { 2 - 3 } & 0.000 & $\mathrm{P}$ \\
\cline { 2 - 3 } & 30 & $\mathrm{~N}$ \\
\hline
\end{tabular}

** Correlation is significant at the 0.05 level

\section{Discussion}

Despite the improved characteristics of composite restorations, polymerization shrinkage remains a challenge and still imposes limitation in the application of direct techniques. This volumetric shrinkage ranges from $2-4 \%[51]$. In this study, a nanofilled, packable and hybrid composites were compared at different filler particle size and different storage intervals (one day, one week, two weeks and three weeks) using artificial saliva[52]. Nanofilled composite was used because of the new technology used in its fabrication where its filler particle size ranges from (0.005-0.01 microns). These very small particles don't react with the visible light and don't produce scattering resulting in significant absorption of light which leads to improvement in modulus of elasticity, depth of cure and esthetics[55, 56].The packable composite was selected for its different advantages. A major advantage is using a new inter-locking particle technology. This technology uses a precisely engineered mixture of different-sized filler particles. These particles are made of a patented 
fluoride-infused glass. When these particles are packed together, the larger partic les mechanically interlock with the smaller particles which lead to improvement of the depth of cure and microhardness[32].

Depth of cure still remains a challenge in the application of direct composite techniques. The depth of polymerization is of vital importance not only in order to achieve optimum physical and mechanical properties but also to ensure that, the clinical problems do not arise due to partially polymerized material in the base of the cavity[4,6]. Depth of cure of dental composites and shrinkage stresses induced during polymerization affect the marginal integrity of composite restorations. For this reason, investigation of depth of cure is of scientific interest[57]. The marginal adaptation andreduction of polymerization shrinkage of composite resin could be improved by increasing depth of cure which could decrease width and length of gaps without interfering with the mechanical properties of the composite restorative material[58].

Evaluation of depth of cure, in this study, was performed using penetrometer. Penetrometer applies a constant stress of $62 \mathrm{MPa}$ allowing consistency of results. Also, penetrometer needs just a single reading to give the value of depth of cure[2]. The results of depth of cure showed that, a significant difference was found between the three tested composites, where the packable co mposite recorded the best depth of cure followed by nanofilled compositethen hybrid composite. This may be attributed to theinterlocking particle technology used in the fabrication of the packable composite, where elongated fibrous filler particles of about 100 micron in length, and/or textured surfaces tend to interlock and resist flow. Rough surfaces, blends of fibrous and particulate fillers produce a packable consistency and enable physical and mechanical properties to be optimized for clin ical performance[59].

In addition, the results were found to be in agreement with the results ofCobb et al.[19],who compared the depth of cure of packable composites, hybrid composites and microfilled composites. They found that, depth of cure of packable composites is better than hybrid composites and microfilled composites. Also, the findings of the present study were close to those ofErsoyet al.[20], who studied the depth of cure and poly merization shrinkage of packable and hybrid composites and reported that, a significant difference was found between materials used, where the packable composites were much better than the hybrid composites used. Because the packable composites consist ofa mixture of different sized filler particles, when packed together result ina precisely engineered mixture that allows light transmission for the deep layers. The results of the present study go with those of Rueggeberget al.[17], who concluded that, the filler type is one of the most in fluential factors in the depth of cure.

On the other hand, material is considered hard if it strongly resists indentation by a hard material such as diamond. Also, hardness is indicative for the ease of finishing of a structure and its resistance to scratching
[24].The Vicker's microhardness test was selected in this study because it is the most accurate, available and simple test for measuring the microhardness of a brittle material like composite restorations[31]. The results of microhadness test showed that, there was a high significant difference between the three composites used where packable composite recorded the highest microhardness values followed by nanofilled composite, then hybrid composite. This may be attributed to the increased depth of cure of the packable composite than the other two composites.

The results of this study were in agreement with the results of Knoblochet al.[35],who studied the microhardness and degree of conversion of packable and microhybrid composites. They concluded that, the packable composites exhibited significantly greater hardness than the other composites. In addition, the results were in agreement with the results ofChoi et al.[32] whostudied the depth of cure, microhardness and polymerization shrinkage of packable composite and non-packable composite. They concluded that, the microhardness of packable composite was higher than non-packable composite when the composite was used in increments not thicker thantwo millimeter.

The results were also close to the results of Manhartet al.[33],who found thatthe filler size and filler content have a high influence on microhardness. Also,the results of this study were in accordance with the results of Mitraet al.[34],who found that microhardness of nanofilled composite was better than the hybrid composite.

In the present study, there was a good correlation between the depth of cure and microhardness of the three composites where $(\mathrm{R}=0.709)$. This could possibly due to that, the increased depth of cure will improve the process of conversion of the monomer to the polymer stage and accelerates the polymerization reaction.

\section{Conclusions}

This study was divided into two parts. The first part dealt with measuring and comparing depth of cure of the three composites, while the second part evaluated and compared the mic rohardness of these composites. Depth of cure and microhardness of the composite specimens was measured using penetrometer and Vicker's microhardness tester, resp ectively. Six measurements for each specimen were recorded and average was calculated. It can be concluded that:

1. A significant differences in depth of cure and microhardness were found between the three composites used.

2. Depth of cure and microhardness of the packable composite were better than the other two composites used.

3. There was a fairly good correlation between the microhardness and the depth of cure for the three composite materials. The results obtained in the present study lead the authors to partially accept the research hypothesis. 


\section{REFERENCES}

[1] Wendt, S.L., Mcinnes, P.M. and Diekinson G.I., The effect of thermocy cling in microleak ge analy sis. Dent. Mat., vol. 8,pp. 181-84,1992

[2] Phillips R.W., Resin composites and polyacid modified resin composite. JADA, pp. 96-102, 1965

[3] Ferracane, J.L., Resin composite - State of the art, Dental materials, vol. 27, pp. 29-38, 2012

[4] Harrington, H. and Wilson, H. J., Depth of cure of radiation-activated materials-effect of the mould material and cavity size. J Dent., vol. 21, pp. 305-11, 1993

[5] Ralph, H. and Esquivel, J., Phillips' science of dental materials $10^{\text {th }}$ edition, Mosby Co., Chapter $15, \mathrm{pp}$. 399-420, 1998

[6] Lelaoup, G., Holoet, E.P., Beoelman, S. and Devaux, J., Raman Scattering Determination of the depth of cure of light activated composites. J Oral Rehabil, vol. 29, pp. 510-15, 2002

[7] Davidson, C.L., Handling the Polymerization Stresses in Resin-Based Restorative Materials, Dental News, Vol. VII, No. IV, pp. 9-13, 2000

[8] Cook, W.D., Factors affecting the depth of cure of UV polymerized composite. J Dent Res, vol. 59,pp. 800-10, 1980

[9] Cook, W.D. and Standish, P., Cure of resin based restorative materials. Aust Dent J, vol. 28, pp. 307-14, 1983

[10] Matsumoto, H., Gres, J.E., Marker, V.A., Okabe, T., Ferracane, J. L. and Harvey, G.A., Depth of cure of visible light-cured resin: clinical simulation. J Prosth Dent, vol. 55, pp. 574-80, 1986

[11] Newman, S.M., Murray, G.A. and Yates, J.L., Visible lights and visible light-activated resin composites. J Prosth Dent, vol. 50, pp. 31-40, 1983

[12] Watts, D.C., Amer, O. and Combe, E.C., Characteristics of visible-light-activated composite systems. BDJ, vol. 156, pp. 209-15, 1984

[13] Swartz, M.L, Li, Y., Phillips, R.W. Moore, B.K. and Roverts, T.A., Effect of filler content and size on properties of composite. J Dent Res, vol. 64, pp. 1396 - 401, 1985

[14] Dunn, WJ., Properties of microfilled composite resin as influenced by filler content. J Can Dent Assoc., vol. 53, pp. 359-65, 1987

[15] Rey es, R., Curing depth of visible light-activated composites. ActaOdontolScand, vol. 42, pp. 23-28, 1989

[16] Atmadja, G. and Bryant, R.W., Some factors influencing the depth of cure of visible light-activated composite resins. JADA, vol. 35, pp. 213-18, 1990

[17] Rueggeberg, F.A., Caughman, W.F., Curtis, J. and Davis, H.C., Factors affecting cure at depths within light activated resin composites. Am J Dent, vol. 6, pp. 91-95, 1993

[18] Nomoto, R., Uchida, K. and Hirasawa, T., Effect of light intensity on polymerization of light cured composite resin. Dent mater J,vol. 3, pp. 198-205, 1994

[19] Cobb, D.S., Macgreger, K.M. and Denehy, G.E., The phy sical properties of packable and conventional posterior resin-based composite: a comparison. JADA, vol. 131, pp. 1610-5, 2001

[20] Ersoy, M., Civelek, A., L'Hotelier, E., Say, E.C. and Soyman, Physical properties of different composites. Dent Mater J., vol. 23, pp. 278-83, 2004

[21] Nikolaos, K., Depth of cure of (PAM-C) and conventional composite using penetrometer: A comparison. J Oral Rehabil, vol. 40, pp. 350-55, 2004

[22] Frauscher, K.E., Ilie, N., Depth of cure and mechanical properties of nano-hybrid resin-based composites with novel and conventional matrix formulation, Clinical Oral Investigations, vol. 16, No. 5, pp. 1425-1434, 2012

[23] Leprince, J.G., Leveque, P., Nysten, B., Gallez, B., Devaux, J., Leloup, G., New insight into the "depth of cure" of dimethacrylate-based dental composites, Dental materials, vol. 28 , pp. 512-520, 2012

[24] Craig, R.G., Powers, J.M. and Wataha, J.C., Rstorative Dental Materials. $8^{\text {th }}$ edition Mosby Co. Chapter 11, pp. 234-54, 2002

[25] Anusavice, K.J., Phillips science of dental materials. $11^{\text {th }}$ edition Saunders Co. Chapter 4, pp.73-101, 2003

[26] Waknine, M., Effect of volume fraction and particle size on Microhardness of composite resin restorations. J Prosth Dent, vol. 75, pp. 265-71, 1984

[27] Chung, K.H., The relationship between composition and properties of posterior resin composites. J Dent Res, vol. 69, pp. 852-56, 1990

[28] Helvatjoglou-Antoniadi, M., Papadogianis, Y., KoliniotouKubia, E. and Kubias, S., Surface Hardness of light-cure and self-cure composite resins. J Prosth Dent, vol. 65, pp. 215-20, 1991

[29] Rueggeberg, F.A., Caughmau, W.F. and Curtis, J.W., Factor affecting cure at depths within light activated resin composite. AM J Dent, vol. 6, pp. 91-5, 1993

[30] Kalliyana, W., Krishnan, V. and Yamnna, V., Effect of Concentration of intiator, exposure time and filler particle size on microhardness. J Oral Rehabil, vol. 25, pp. 747-51, 1998

[31] Toledao, M., Oserio, E. and Oseerio, R., Microhardness of selected restorative materials. J of Prosth Dent, vol. 81, pp. 610-15, 1999

[32] Choi, K.K., Ferracane, J.L., Hilton, T.J. and Charlton, D., Properties of packable dental composite. J Esthet Dent, vol. 12, pp. 216-26, 2000

[33] Manhart, J., Kunzelmann, K.H., Chen, H.Y. and Hickel, R., Mechanical properties of light cured packable composite resins. Dent Mat, vol. 16, pp. 33-40, 2000

[34] Mitra, S.B., Wu, D. and Holmes, B.N., An application of nanotechnology in advanced dental materials. JADA, vol. 134, pp. 1382-90, 2003

[35] Knobloch, L.A., Kerby, R.E., Clelland, N. and Lee, J.: Hardness and degree of conversion of posterior packable composites. Oper Dent, vol. 29, pp. 642-49, 2004

[36] Soares, C.J., Pizi, E.C.,Fonseca, R.B. and Martins, L.R. Mechanical properties of light cured Composites. Oper Dent, vol. 30, pp. 389-94, 2005 
[37] Kwon, Y.H., Kang, S.I., Park, J.K. and Kim, H.I., Effect of irridiation mode on polmerization of dental composites. J Biomed Mat Res, vol. 30, pp. 470-77, 2006

[38] IhsanHubbezoglu, GirayBolayir, Orhan Murat Dogan, ArifeDogan, Ali Özer, BülentBek, Microhardness Evaluation of Resin Composites Polymerized by Three Different Light Sources, Dental Materials Journal, vol. 26, No. 6, pp. 845-853, 2007

[39] Korkmaz, Y., Ozel, E., Attar, N. and Aksoy, G., The Influence of One-step Polishing Systems on the Surface Roughness and Microhardness of Nanocomposites. Operative Dentistry, vol. 33, No. 1, pp. 44-50, 2008. doi: http://dx.doi.org/10.2341/07-28

[40] Topcu, F.T., Erdemir, U., Sahinkesen, G., Yildiz, E., Uslan, I., Acikel, C., Evaluation of microhardness, surface roughness, and wear behavior of different types of resin composites polymerized with two different light sources, Journal of Biomedical Materials Research Part B: Applied Biomaterials, vol. 92B, No. 2, pp. 470-478, 2010

[41] Groninger, A.I.S., Soares, G.P., Sasaki, R.T., Ambrosano, G.M.B., Lovadino, J.R. and A guiar, F.H.B., Microhardness of nanofilled composite resin light-cured by LED or QTH units with different times, Brazilian Journal of Oral Sciences, vol. 10, No. 3, pp. 189-192, 2011

[42] Poggio, C., Lombardini, M ., Gaviati, S . and Chiesa, M., Evaluation of Vickers hardness and depth of cure of six composite resins photo-activated with different polymerization modes, J Conserv Dent. vol. 15, No. 3, pp. 237-241, 2012. doi: 10.4103/0972-0707.97946

[43] Flury, S., Hayoz, S., Peutzfeldt, A., Hüsler, J., Lussi, A., Depth of cure of resin composites: Is the ISO 4049 method suitable for bulk fill materials? Dental materials, vol. $28, \mathrm{pp}$. 521-528, 2012

[44] El-Nawawy, M., Koraitim, L., Abouelatta, O., and Hegazi, H., Marginal Adaptation of Nanofilled, Packable and Hybrid Dental Composite Resins Stored in Artificial Saliva, American Journal of Biomedical En gineering, vol. 2, No. 3, pp. 105-114, 2012

[45] Mathew, M.E.K., Nair, P. and Krishnan, K., Bonding agent is a decisive factor in determining the marginal leakage of dental composite. J. Oral Rehabil., vol. 28, pp. 68-77, 2001

[46] Han, B., Attin, T., Grofke, M. and Hellwig, E., Influence of resin cement viscosity on microlekage of ceramic in lays. Dent. Mat., vol. 17, pp. 191-196, 2001

[47] Brend, D. and Geurner, W., Molar fracture resistance after adhesive restoration with ceramic in lays or resin based composite., Am. J. Dent., vol. 14, pp. 216-220, 2001

[48] Brannstrom, M., The cause of post-restorative sensitivity and its prevention. J. Endo., vol.12, pp. 520-25, 1986

[49] Phillips, R.W., New concepts in materials used for restorative dentistry. JADA, vol. 70, pp. 652-58, 1965

[50] Ralph, H. and Esquivel, J., Phillips' science of dental materials., 10thed., Mosby Co., Chapter 15, pp. 399-420, 1998

[51] Krejici, I., Lutz, F. and Reimer, M., Marginal adaptation and fit of adhesive ceramic in lay., J. Dent., vol. 21, pp. 39-46, 1993

[52] Moore, B.K., Platt, J.A., Borges, G., Chu, T.-M.G. and Katsilieri, I., Depth of cure of dental resin composites: ISO 4049 depth and microhardness of types of materials and shades, Operative Dentistry, vol. 33, No. 4, pp. 408-412, 2008

[53] Fennis, W.M.M., Ray, N.J., Creugers, N.H.J., Kreulen, C.M., Microhardness of resin composite materials light- cured through fiber reinforced composite, Dental Materials, vol. 25, pp. 947-951, 2009

[54] Krejci, I., Lutz, F. and Gaust, Schil, Wear and marginal adaptation of composite resin inlays, J Prosthet Dent, vol. 72, pp. 233-44, 1994

[55] Stephen, C. and Duane, F., Dental materials, the art and science of operative dentistry, 3rd ed Mosby Co., pp. 206-88, 1998

[56] Norpert, N., Noszner, S. and Simone, K., Nanotechnology for dental composite. Dent Mat, vol. 19, pp. 725-55, 2004

[57] Loukidis, M., Rahiotis, C. and Kakboura, A., Curing efficiency of various types of light-curing unit. EUR J Oral Sci, vol. 112, pp. 89-94, 2004

[58] Moon, H.J., Effect of depth of cure on marginal adaptation. J Oral Rehabil, vol. 31, pp. 258-64, 2004

[59] Rawls, R.H. and Upshaw, E.J., Restorative resins. Phillips' science of dental material 11th Ed., Chapter 15, pp. 399-441, 2003 